\title{
Targeted disruption of adenosine kinase in myeloid monocyte cells increases osteoclastogenesis and bone resorption in mice
}

\author{
QIUYING YE ${ }^{1 *}$, GE LI $^{2 *}$, SHUHUA LIU ${ }^{2}$, YALUN GUAN $^{2}$, YUNFENG LI $^{2}$, JINLING LI $^{2,3}$, \\ HUANHUAN JIA ${ }^{2}$, XUEJIAO LI ${ }^{2}$, QINGNAN LI ${ }^{2,4}$, REN HUANG ${ }^{2}$, HUI WANG ${ }^{1,3}$ and YU ZHANG ${ }^{2}$ \\ ${ }^{1}$ Department of Food and Drugs, Qingyuan Polytechnic, Qingyuan, Guangdong 511510; \\ ${ }^{2}$ Guangdong Laboratory Animals Monitoring Institute, Guangdong Provincial Key Laboratory of Laboratory Animals, \\ Guangzhou, Guangdong 510663; ${ }^{3}$ School of Traditional Chinese Medicine and ${ }^{4}$ Department of Life Science, \\ Guangdong Pharmaceutical University, Guangzhou, Guangdong 510006, P.R. China
}

Received October 18, 2017; Accepted January 5, 2018

DOI: $10.3892 / \mathrm{ijmm} .2018 .3394$

\begin{abstract}
Adenosine kinase (ADK) serves an important role in intracellular adenosine clearance via phosphorylating adenosine to AMP. The role of adenosine and its receptors in the maintenance of bone homeostasis is well studied, particularly in osteoclastogenesis and bone resorption; however, the function of ADK in bone metabolism is still unclear. In the present study, utilizing the cre/floxp recombination system, mice with conditional loss of ADK function in myeloid monocyte cells were used to assess the effect of ADK deficiency on bone metabolism. Mice were evaluated by means of gross observation and bone histomorphometric analysis. Ex vivo osteoclast differentiation and bone resorption were also examined using genetic deletion and pharmacologic inhibition of ADK in osteoclasts. Compared with control mice, the results of the present study demonstrate that adult mice lacking ADK in the myeloid monocyte cells had reduced body weight and nasoanal length. The results of bone histomorphometric analysis revealed that bone mass was significantly decreased and osteoclastic parameters were increased in the study mice. Furthermore, in vitro cell culture revealed that inhibition of ADK function promoted osteoclast differentiation and bone resorption. Osteoclast-associated gene expression, including
\end{abstract}

Correspondence to: Professor Yu Zhang, Guangdong Laboratory Animals Monitoring Institute, Guangdong Provincial Key Laboratory of Laboratory Animals, 11 Fengxin Road, Guangzhou Science City, Guangzhou, Guangdong 510663, P.R. China

E-mail: zhy@gdlami.com

Professor Hui Wang, Department of Food and Drugs, Qingyuan Polytechnic, Panlong Park, Dongcheng Street, Qingcheng, Qingyuan, Guangdong 511510, P.R. China

E-mail: gdwanghui2006@126.com

*Contributed equally

Key words: adenosine kinase, myeloid monocyte cell, growth retardation, osteoclastogenesis, bone resorption tartrate-resistant acid phosphatase, nuclear factor of activated T-cells, cytoplasmic 1, matrix metalloproteinase 9, Cathepsin $\mathrm{K}$ and calcitonin receptor, was also significantly increased. These results suggest that mice with ADK deficiency have reduced bone formation due to increased osteoclastogenesis and bone resorption. The present study provides further insight into the mechanism by which ADK serves a key role in bone metabolism.

\section{Introduction}

Adenosine kinase (ADK) is the key metabolic regulator of the purine ribonucleoside adenosine and is essential for intracellular adenosine metabolic clearance via phosphorylating adenosine to AMP based on its low $K m$ (1). ADK is expressed in most vital organs that require metabolic adenosine clearance, in particular the liver and placenta (2). ADK controls specific organ functions via a combination of adenosine receptor-dependent and -independent mechanisms (1). Changes in adenosine homeostasis may activate the four adenosine-associated G-protein-coupled receptors, alter energy metabolism and regulate DNA methylation (3). A number of studies have demonstrated that ADK serves important roles in several diseases, including epilepsy (4), traumatic brain injury (5), stroke (6), diabetes (7) and cancer (8).

Bone is a highly dynamic organ that is constantly undergoing remodeling by means of bone formation and resorption in the adult skeleton (9). Previous studies have investigated the role of adenosine and its four $\mathrm{G}$ protein-coupled receptors in the maintenance of bone homeostasis in vivo and in vitro, particularly adenosines association with osteoclastogenesis and bone resorption in rodents and humans (10). Previous reports suggest that activating adenosine $A_{1}$ receptor (A1R) and adenosine $\mathrm{A}_{2 \mathrm{~B}}$ receptor (A2BR) promotes osteoclastogenesis; however, adenosine $A_{2 A}$ receptor (A2AR) activation has the opposite effect (11-14) and adenosine $A_{3}$ receptor (A3R) activation indirectly inhibits osteoclastogenesis due to its anti-inflammatory effect (15).

ADK deficiency results in the accumulation of intracellular adenosine and a decrease in AMP, ADP and ATP, which in turn leads to disordered purinergic signaling (1). A recent 
clinical investigation based on next generation sequencing revealed that patients deficient in ADK with intellectual disabilities also presented with short stature, frontal bossing and slender hands and fingers (16). In a mouse model, genetic deletion of ADK resulted in mice succumbing within 14 days of birth whereas mice with ADK deficiency exhibited reduced body weight and length (17). However, the function of ADK in bone metabolism is still unknown.

Osteoclasts are the primary bone-resorbing cells and are thought to be derived from the monocyte-macrophage lineage (18). In the present study, a mouse model with ADK knockout in myeloid monocyte cells (ADK ${ }^{\mathrm{MMC}-\mathrm{KO}}$ ) was established via Cre/LoxP site-specific recombination. The effect of ADK on bone metabolism was assessed by gross observation and bone histomorphometric analysis in vivo to ascertain whether there were changes in bone homeostasis. In addition, osteoclast differentiation and bone resorption were examined in vitro by genetic deletion and pharmacologic inhibition of ADK in osteoclasts.

\section{Materials and methods}

Animals. All animal experiments in this study were approved and supervised by the Institutional Animal Care and Use Committee (IACUC No. 2014027) of Guangdong Laboratory Animals Monitoring Institute (Guangzhou, China). ADK ${ }^{\text {flox/flox }}$ (C57BL/6 background) mice (hereafter referred to as ADK ${ }^{\mathrm{WT}}$ ) provided by Professor Yuqing Huo (Vascular Biology Center, Department of Cellular Biology and Anatomy, Medical College of Georgia, Augusta University, Augusta, GA, USA) (19) were mated to lysozyme 2-Cre mice $\left(\right.$ lysM $^{\text {cre }}$; stock no. 004781; Jackson Laboratory, Farmington, CT, USA), in which the Cre recombinase gene is knocked into the lysozyme 2 locus and is specifically expressed in myeloid monocyte cells (20). Mice with ADK-deficient myeloid monocyte cells (ADK ${ }^{\text {MMC-KO})}$ were generated by mating $\mathrm{ADK}^{\text {flox/flox}}{ }^{\mathrm{x} l y s} \mathrm{M}^{\text {cre }}$ mice with $\mathrm{ADK}^{\text {flox/flox }}$ mice. All mice were provided with water and a standard chow diet ad libitum. Mice were maintained in a specific pathogen-free facility with a $12 \mathrm{~h}$ light/dark cycle at $23 \pm 2^{\circ} \mathrm{C}$ and $50 \pm 10 \%$ relative humidity.

For the in vivo experiment, 4-month-old male $\mathrm{ADK}^{\mathrm{MMC}-\mathrm{KO}}$ (23-25 g; $\mathrm{n}=10)$ and $\mathrm{ADK}^{\mathrm{WT}}(27-29 \mathrm{~g} ; \mathrm{n}=10)$ mice were used for gross apperance and bone histomorphometric analysis, with $\mathrm{ADK}^{\mathrm{WT}}$ as the control. For the in vitro experiment, 2-month-old male $\mathrm{ADK}^{\mathrm{MMC}-\mathrm{KO}}$ (21-23 g; $\left.\mathrm{n}=10\right)$ and $\mathrm{ADK}^{\mathrm{WT}}$ mice $(25-27 \mathrm{~g}$; $\mathrm{n}=10$ ) were used for osteoclastogenesis and bone resorption analysis. In addition, 2-month-old male $\mathrm{ADK}^{\mathrm{WT}}$ mice $(25-27 \mathrm{~g}$; $\mathrm{n}=20)$ were assigned to either an ABT-702-treated group $(\mathrm{n}=10)$ or a vehicle control group $(\mathrm{n}=10)$ for in vitro osteoclastogenesis and bone resorption analysis.

Cell culture. Murine osteoclasts were generated from bone marrow cells as previously described (21). Briefly, following $\mathrm{CO}_{2}$ euthanasia, primary $\mathrm{ADK}^{\mathrm{MMC}-\mathrm{KO}}$ or $\mathrm{ADK}^{\mathrm{WT}}$ mouse bone marrow cells were isolated by flushing the tibia and femur of 2-month-old male mice with $\alpha$-modified Eagle's medium ( $\alpha$-MEM; Thermo Fisher Scientific, Inc., Waltham, MA, USA). Cells were subsequently centrifuged $(1,000 \mathrm{x} \mathrm{g})$ at $4^{\circ} \mathrm{C}$ for $5 \mathrm{~min}$ and incubated in $\alpha$-MEM containing $10 \%$ (v/v) fetal bovine serum (Thermo Fisher Scientific, Inc.), penicillin-streptomycin $(100 \mathrm{U} / \mathrm{ml})$ and $1 \%(\mathrm{w} / \mathrm{v})$ glutamine (Sigma Aldrich; Merck KGaA, Darmstadt, Germany) overnight at $37^{\circ} \mathrm{C}$ in a humidified atmosphere containing $5 \% \mathrm{CO}_{2}$. To generate bone marrow-derived macrophages, non-adherent cells were collected, plated onto 24 -well plates $\left(1 \times 10^{6}\right.$ cells/well) and cultured at $37^{\circ} \mathrm{C}$ in a humidified atmosphere containing $5 \% \mathrm{CO}_{2}$ with $25 \mathrm{ng} / \mathrm{ml}$ macrophage colony-stimulating factor (M-CSF; R\&D Systems, Inc., Minneapolis, MN, USA) for 3 days in $\alpha$-MEM. Cells were then used for osteoclast differentiation or ADK western blot analysis. To generate osteoclasts, bone marrow-derived macrophages were incubated at $37^{\circ} \mathrm{C}$ in a humidified atmosphere containing $5 \% \mathrm{CO}_{2}$ with $\alpha$-MEM containing $25 \mathrm{ng} / \mathrm{ml} \mathrm{M-CSF}$ and $30 \mathrm{ng} / \mathrm{ml}$ receptor activator of nuclear factor kappa-B ligand (RANKL; R\&D Systems, Inc.) for 5 days. To evaluate the effect of ADK inhibition on osteoclast differentiation, ABT-702 dihydrochloride (Tocris; Bio-Techne, Minneapolis, MN, USA), a potent non-nucleoside ADK inhibitor, was pre-dissolved in 5\% EtOH and the solution was diluted with osteoclast differentiation medium as described for cell culture. All assays were performed in triplicate.

Western blotting. Total protein was extracted from bone marrow-derived macrophages using radioimmunoprecipitation assay buffer (Sigma Aldrich; Merck KGaA) according to the manufacturer's protocol. Protein was quantified using a bicinchoninic acid assay and $20 \mu \mathrm{g}$ samples were separated by $10 \%$ SDS-PAGE and transferred onto nitrocellulose membranes. The membranes were blocked with $5 \%(\mathrm{w} / \mathrm{v})$ non-fat dry milk in TBST buffer for $1 \mathrm{~h}$ at $4^{\circ} \mathrm{C}$. Rabbit monoclonal antibodies against ADK (Sigma Aldrich; Merck KGaA; cat no. SAB2701969; 1:1,000) and GAPDH (Sigma Aldrich; Merck KGaA; cat. no. G9545, 1:2,500) were used to assess ADK protein levels in cultured cell lysates. The membranes were incubated with the primary antibodies in $1 \%$ bovine serum albumin (Sigma Aldrich; Merck KGaA) overnight at $4^{\circ} \mathrm{C}$ and washed three times with TBST. Subsequently, membranes were incubated with horseradish peroxidase-conjugated secondary goat anti rabbit antibody (Invitrogen; Thermo Fisher Scientific, Inc.; cat. no. $31460 ; 1: 2,000)$ in non-fat dry milk for $1 \mathrm{~h}$ at room temperature and washed three times with TBST. Membranes were visualized using West Pico Chemiluminescent Substrate (Thermo Fisher Scientific, Inc.). Bands were quantified using Image Lab 5.0 (Bio-Rad Laboratories, Inc., Hercules, CA, USA).

Tartrate-resistant acid phosphatase (TRAP) activity assay. TRAP staining was performed using an Acid Phosphatase Leukocyte (TRAP) kit (Sigma Aldrich; Merck KGaA) according to the manufacturer's protocol. Briefly, osteoclasts differentiated from bone marrow cells were fixed in $37 \%$ formaldehyde for $30 \mathrm{sec}$ at $4^{\circ} \mathrm{C}$ and rinsed thoroughly in deionized water. TRAP staining solution was mixed and preheated to $37^{\circ} \mathrm{C}$ and the fixed cells were added and incubated for $1 \mathrm{~h}$ at $37^{\circ} \mathrm{C}$. Cells were counterstained with hematoxylin for $30 \mathrm{sec}$ at room temperature and the number of osteoclasts (defined as multinuclear TRAP-positive cells) per well was counted under a bright field inverted microscope (magnification, x200; DMI3000; Leica Microsystems GmbH, Wetzlar, Germany). 
Bone resorption assay and assessments. A bone resorption assay was performed as previously described (22). Briefly, bone marrow-derived macrophages $\left(1 \times 10^{6}\right.$ cells/well) were seeded in Osteo-Assay Surface 24-well plates (Sigma Aldrich; Merck KGaA); osteoclastic differentiation and culture were performed as above. Plates were examined under a bright field inverted microscope (magnification, x10) and images of 10 random fields/well were captured. The percentage and number of resorption areas were calculated using with ImageJ software 1.50i (National Institutes of Health, Bethesda, MD, USA).

Reverse transcription-quantitative polymerase chain reaction $(R T-q P C R)$. Total RNA was extracted from cultured cells using TRIzol (Invitrogen; Thermo Fisher Scientific, Inc.) and RT was performed using the PrimeScript ${ }^{\mathrm{TM}}$ RT reagent kit (Takara Bio, Inc., Otsu, Japan) at $37^{\circ} \mathrm{C}$ for $30 \mathrm{~min}$ and $85^{\circ} \mathrm{C}$ for $1 \mathrm{~min}$ according to the manufacturer's protocol. All primers were provided by Invitrogen (Thermo Fisher Scientific, Inc.) and were as follows: TRAP, forward 5'-ACC ATTGTTAGCCACATACG-3' and reverse 5'-GTGAAACCG CAAGTAGCC-3; matrix metalloproteinase-9 (MMP-9), forward 5'-AGTTTGGTGTCGCGGAGCAC-3' and reverse 5'-TACATGAGCGCTTCCGGCAC-3'; nuclear factor of activated T-cells, cytoplasmic 1 (NFATc1), forward 5'-GGG TCAGTGTGACCGAAGAT-3' and reverse 5'-GGAAGT CAGAAGTGGGTGGA-3'; proto-oncogene tyrosine-protein kinase Src (c-Src), forward 5'-CCAGGCTGAGGAGTGGTA CT-3' and reverse 5'-CAGCTTGCGGATCTTGTAGT-3'; FBJ osteosarcoma oncogene (c-FOS), forward 5'-CCAGTCAAG AGCATCAGCAA-3' and reverse 5'-AAGTAGTGCAGCCCG GAGTA-3'; Cathepsin K (CtsK), forward 5'-GAAGAAGAC TCACCAGAAGCAG-3' and reverse 5'-TCCAGGTTATGG GCAGAGATT-3'; calcitonin receptor (CTR), forward 5'-CCT GACAGCAACCGAACC-3' and reverse 5'-GCAACCAAA GCAGCAATC-3'; GAPDH, forward 5'-TGTAGACCATGT AGTTGAGGTCA-3' and reverse 5'-AGGTCGGTGTGAACG GATTTG-3'. qPCR reactions were performed as follows: $95^{\circ} \mathrm{C}$ for $30 \mathrm{sec}$ followed by 40 cycles of $95^{\circ} \mathrm{C}$ for $5 \mathrm{sec}$ and $60^{\circ} \mathrm{C}$ for $34 \mathrm{sec}$, using an ABI-7500 Fast Real-Time PCR System (Applied Biosystems; Thermo Fisher Scientific, Inc.) in a total volume of $25 \mu \mathrm{l}$ containing $2 \mu \mathrm{M}$ primers and $12.5 \mu \mathrm{l}$ of the SYBR $^{\circledR}$ Premix Ex Taq ${ }^{\mathrm{TM}}$ (Takara Bio, Inc.). Results were quantified using the $2^{-\Delta \Delta \mathrm{Cq}}$ method (23).

Bone histomorphometric analysis. The proximal tibia metaphysis and tibia shaft were fixed at $4^{\circ} \mathrm{C}$ for $48 \mathrm{~h}$ in $4 \%$ paraformaldehyde and decalcified in $10 \%$ EDTA for 3-4 weeks. Tibias were subsequently embedded in paraffin and cut into $4-\mu \mathrm{m}$ sections. Following deparaffinization and rehydration, sections were stained with hematoxylin and eosin (H\&E) for $1 \mathrm{~min}$ at room temperature. Terminology recommended by the Histomorphometry Nomenclature Committee of the American Society for Bone and Mineral Research (24) and the BIOQUANT OSTEO 2009 morphometric measuring system (Bioquant Image Analysis Corporation, Nashville, TN, USA) were used in the present study. The proximal tibia metaphysis histomorphometric perimeters were determined by measuring the areas under 1-3 $\mu \mathrm{m}$ from the growth plate excluding the primary spongiosa and trabeculae connected to the cortical bone. The lower end of the tibia was separated from the fibula and prepared for tibia shaft transection and histomorphometric perimeters were determined.

Statistical analysis. Two-tailed unpaired t-tests with Welch's correction were used for comparisons between the two groups, using GraphPad Prism 6.01 (GraphPad Software, Inc., La Jolla, CA, USA). Data are presented as the mean + standard error of the mean of three independent experiments. $\mathrm{P}<0.05$ was considered to indicate a statistically significant difference.

\section{Results}

Spontaneous dwarfism in ADK ${ }^{M M C-K O}$ mice. Primordial dwarfism was observed in $\mathrm{ADK}^{\mathrm{MMC}-\mathrm{KO}}$ mice. Compared with male $\mathrm{ADK}^{\mathrm{WT}}$ mice, the appearance of $\mathrm{ADK}^{\mathrm{MMC}-\mathrm{KO}}$ mice was not markedly different, however the mice appeared markedly smaller at 4 months old (Fig. 1A). Measurements revealed that the body weight and nasoanal length of $\mathrm{ADK}^{\mathrm{MMC}-\mathrm{KO}}$ mice was significantly decreased compared with $\mathrm{ADK}^{\mathrm{WT}}$ mice $(\mathrm{P}<0.0001$; Fig. 1B).

To investigate whether the dwarfism observed in ADK $^{\text {MMC-KO }}$ mice was associated with skeletal growth, the tibia and femur were assessed. The results demonstrated that the tibia and femur lengths were significantly shorter in $\mathrm{ADK}^{\mathrm{MMC}-\mathrm{KO}}$ mice compared with $\mathrm{ADK}^{\mathrm{WT}}$ mice $(\mathrm{P}<0.0001$; Fig. 1C). Furthermore, it was demonstrated that the tibia and femur weigh significantly less in $\mathrm{ADK}^{\mathrm{MMC}-\mathrm{KO}}$ mice compared with $\mathrm{ADK}^{\mathrm{WT}}$ mice $(\mathrm{P}<0.0001$; Fig. 1D). These results suggest that conditional ADK knockout in myeloid monocyte cells causes skeletal dysostosis in mice.

Abnormal bone formation in $A D K^{M M C-K O}$ mice. To further investigate the causes of skeletal dysostosis in $\mathrm{ADK}^{\mathrm{MMC}-\mathrm{KO}}$ mice, bone samples underwent histomorphometric analysis. In the proximal tibia metaphysis, fewer bone trabeculae and a smaller volume of trabecular bones was observed in $\mathrm{ADK}^{\mathrm{MMC}-\mathrm{KO}}$ mice compared with $\mathrm{ADK}^{\mathrm{WT}}$ mice (Fig. 2A). Quantitative analysis of bone trabecular parameters revealed that the bone area (\%Tb.Ar; $\mathrm{P}<0.01)$, trabecular thickness (Tb.Th; $\mathrm{P}<0.05)$ and trabecular number (Tb.N; $\mathrm{P}<0.05)$ were significantly decreased in $\mathrm{ADK}^{\mathrm{MMC}-\mathrm{KO}}$ mice compared with $\mathrm{ADK}^{\mathrm{WT}}$ mice (Fig. 2B). Furthermore, trabecular separation (Tb.Sp; $\mathrm{P}<0.05$ ) was significantly increased in ADK ${ }^{\text {МMС-КО }}$ mice compared with ADK ${ }^{\mathrm{WT}}$ mice (Fig. 2B). Analysis of osteoclastic parameters revealed that the percentage of trabecular osteoclast surface to bone surface (\%Oc.S/BS; P<0.01) and ratio of osteoclast number to bone surface (N.Oc/BS; $\mathrm{P}<0.01$ ) were significantly increased in $\mathrm{ADK}^{\mathrm{MMC}-\mathrm{KO}}$ mice compared with $\mathrm{ADK}^{\mathrm{WT}}$ mice (Fig. 2B). However, the adherent perimeter of osteoblasts (\%Ob.S/BS; $\mathrm{P}<0.01)$ and number of osteoblasts per unit bone surface $(\mathrm{N} . \mathrm{Ob} / \mathrm{BS} ; \mathrm{P}<0.01)$, were significantly lower in in $\mathrm{ADK}^{\mathrm{MMC}-\mathrm{KO}}$ mice compared with $\mathrm{ADK}^{\mathrm{WT}}$ mice (Fig. 2B).

The tibial shaft of in ADK ${ }^{\text {MMC-KO }}$ mice was also examined and, compared with $\mathrm{ADK}^{\mathrm{WT}}$ mice, the cortical bone was markedly reduced and an expansive bone marrow cavity was observed (Fig. 2C). Quantitative analysis revealed that the percentage of cortical bone area was significantly decreased (\% Ct.Ar, $\mathrm{P}<0.01)$ and the bone marrow cavity area was 

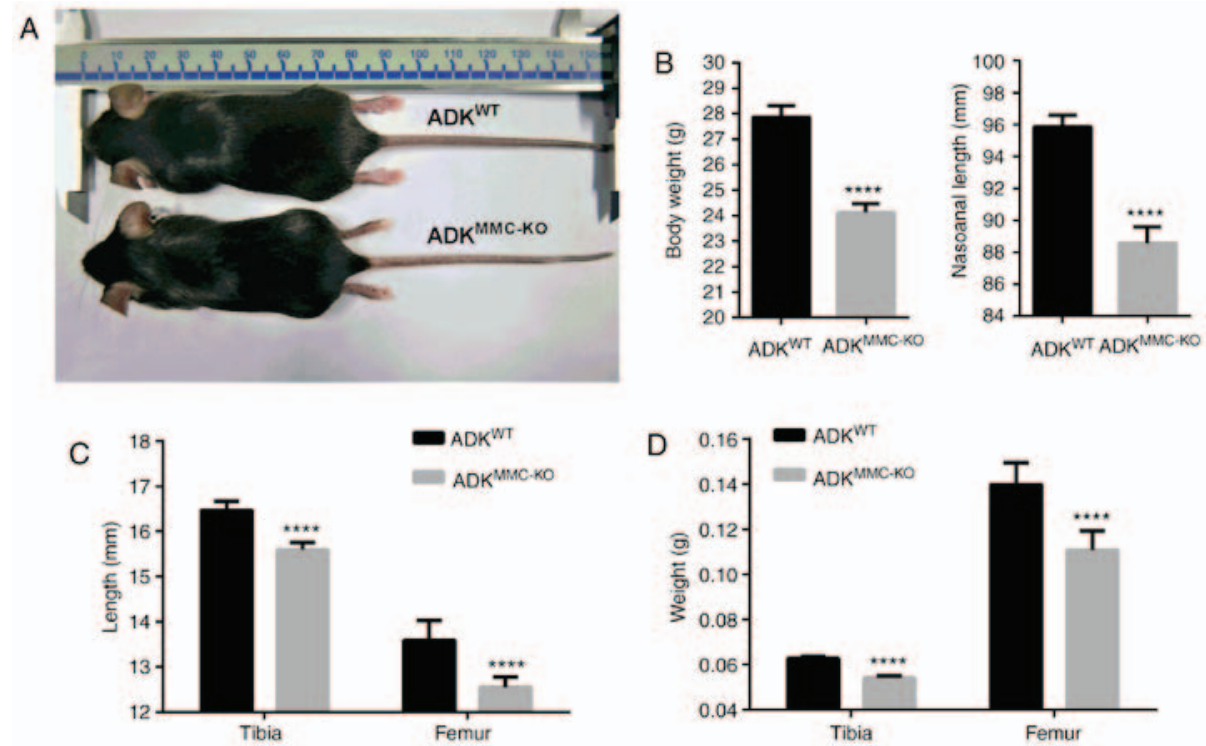

Figure 1. Longitudinal growth retardation in $\mathrm{ADK}^{\mathrm{MMC}-\mathrm{KO}}$ mice. (A) Gross appearance of 4-month male $\mathrm{ADK}^{\mathrm{WT}}$ and $\mathrm{ADK}^{\mathrm{MMc}-\mathrm{KO}}$ mice. Quantitative analysis of (B) body weight and nasoanal length, (C) tibia and femur length and (D) tibia and femur weight in 4-month-old male $\mathrm{ADK}^{\mathrm{WT}}$ and $\mathrm{ADK}^{\mathrm{MMC}-\mathrm{KO}}$ mice. $\mathrm{n}=10$ per group. ${ }^{* * * * *} \mathrm{P}<0.0001$ vs. $\mathrm{ADK}^{\mathrm{WT}}$ mice. ADK, adenosine kinase; $\mathrm{ADK}^{\mathrm{WT}}$, ADK wild type; $\mathrm{ADK}^{\mathrm{MMC}-\mathrm{KO}}$, ADK knockout in myeloid monocyte cells.

A

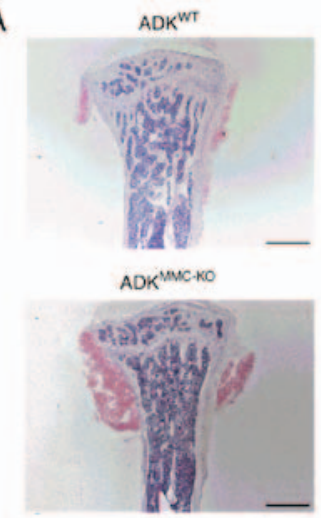

C

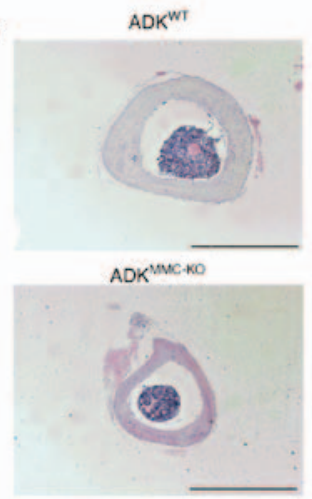

B
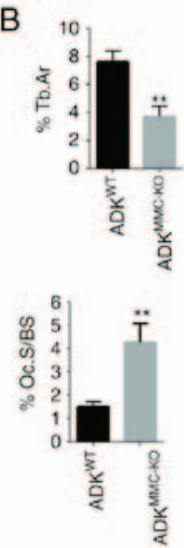

D

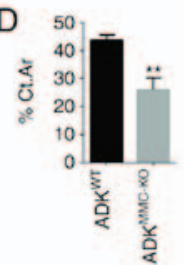

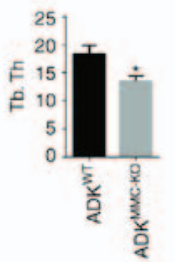
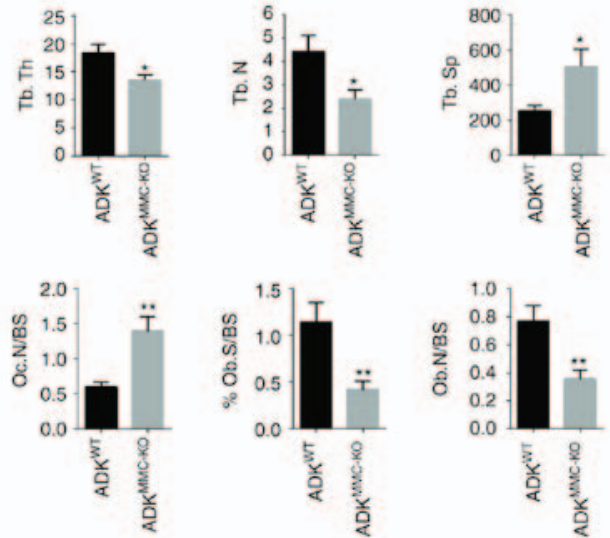

Figure 2. Histological analysis of the tibia from $\mathrm{ADK}^{\mathrm{MMC}-\mathrm{KO}}$ mice. (A) H\&E staining of the proximal tibia metaphysis of $\mathrm{ADK}{ }^{\mathrm{MMC}-\mathrm{KO}}$ and $\mathrm{ADK}{ }^{\mathrm{WT}}$ mice. (B) Bone histomorphometric analysis of \%Tb.Ar, Tb.Th, Tb.N, Tb.Sp, \%Oc.S/BS, N.Oc/BS, \%Ob.S/BS and N.Ob/BS for ADK ${ }^{\mathrm{WT}}$ and ADK ${ }^{\mathrm{MMC}-\mathrm{KO}}$ mice. (C) H\&E staining of the tibia shaft from ADK ${ }^{\mathrm{MMC}-\mathrm{KO}}$ and $\mathrm{ADK}^{\mathrm{WT}}$ mice. (D) Bone histomorphometric analysis of \%Ct.Ar and \%Ma.Ar in the middle part of tibia shaft from $\mathrm{ADK}^{\mathrm{WT}}$ and $\mathrm{ADK}^{\mathrm{MMC}-\mathrm{KO}}$ mice. $\mathrm{n}=10$ per group. Scale bar=200 $\mu \mathrm{m} .{ }^{*} \mathrm{P}<0.005$ and ${ }^{* *} \mathrm{P}<0.01$ vs. ADK ${ }^{\mathrm{WT}}$. ADK, adenosine kinase; ADK ${ }^{\mathrm{WT}}$, ADK wild type; ADK ${ }^{\mathrm{MMC}-\mathrm{KO}}$, ADK knockout in myeloid monocyte cells; H\&E, hematoxylin and eosin; \% Tb.Ar, percentage of bone area; Tb.Th, trabecular thickness; Tb.N, trabecular number; Tb.Sp, trabecular separation; \%Oc.S/BS, percentage of adherent perimeter cells; N.Oc/BS, number of osteoclasts per unit bone surface; \%Ob.S/BS, percentage of adherent perimeter osteoblasts; N.Ob/OS, number of osteoblasts per unit bone surface; \%Ct.Ar, percentage of cortical bone area; \%Ma.Ar, bone marrow cavity area.

significantly increased (\%Ma.Ar; $\mathrm{P}<0.01)$ in $\mathrm{ADK}^{\mathrm{MMC}-\mathrm{KO}}$ mice (Fig. 2D). These results suggest that conditional ADK knockout in myeloid monocyte cells causes defective bone formation in $\mathrm{ADK}^{\mathrm{MMC-KO}}$ mice. 


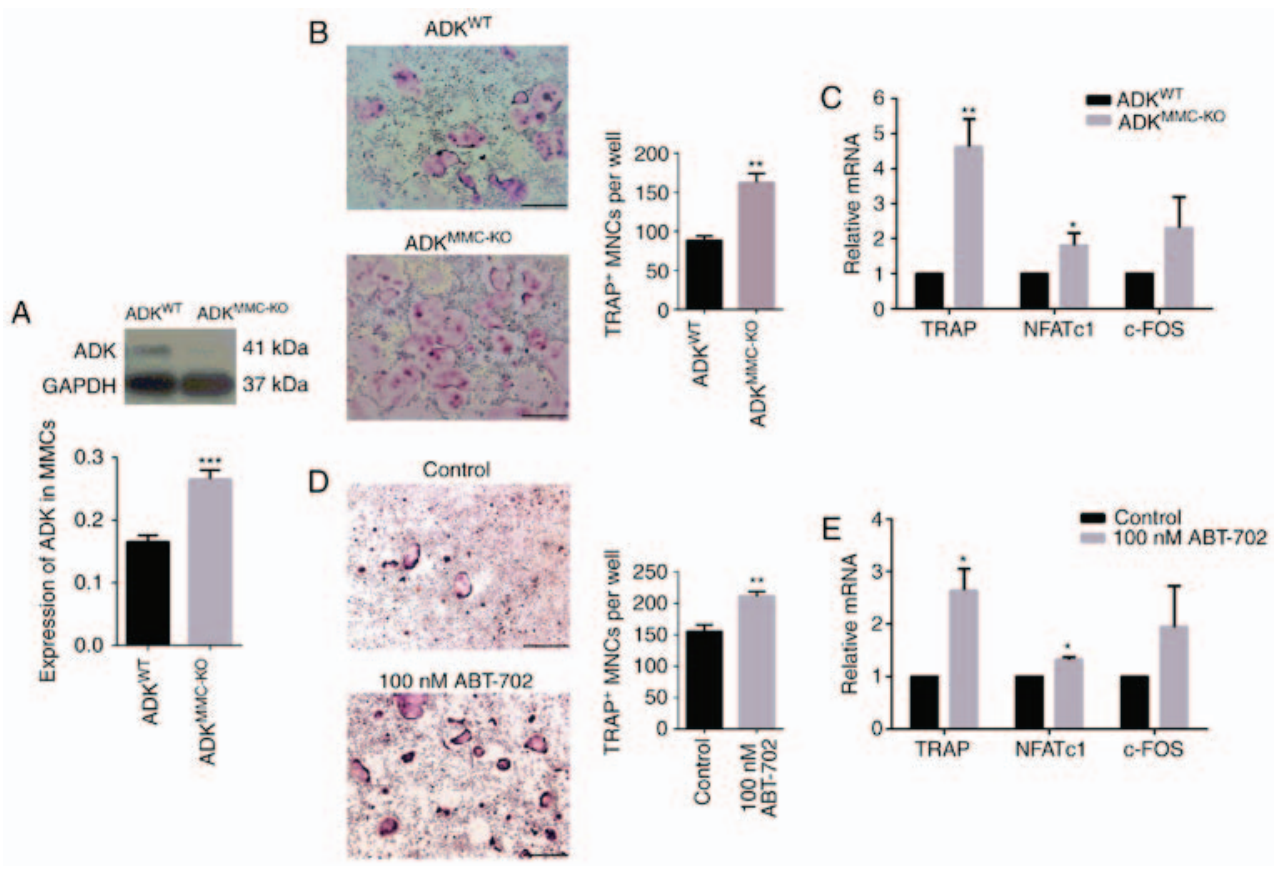

Figure 3. ADK knockdown enhances osteoclastogenesis and the expression of associated genes. (A) Expression of ADK protein in BMMs from 2-month male $\mathrm{ADK}^{\mathrm{WT}}$ and $\mathrm{ADK}{ }^{\mathrm{MMC}-\mathrm{KO}}$ mice. (B) TRAP staining of osteoclasts generated from BMMs of $\mathrm{ADK}^{\mathrm{WT}}$ and $\mathrm{ADK}^{\mathrm{MMC}-\mathrm{KO}}$ mice. (C) Relative TRAP, NFATc1 and c-FOS mRNA in osteoclasts generated from BMMs of ADK ${ }^{\mathrm{WT}}$ and $\mathrm{ADK}^{\mathrm{MMC}-\mathrm{KO}}$ mice. (D) TRAP staining analysis of osteoclasts generated from BMMs of $\mathrm{ADK}^{\mathrm{WT}}$ mice treated with $100 \mathrm{nM}$ ABT-702. (E) Relative TRAP, NFATc1 and c-FOS mRNA levels in osteoclasts generated from BMMs of ADKWT mice treated with $100 \mathrm{nM}$ ABT-702 Scale bar $=500 \mu \mathrm{m} .{ }^{*} \mathrm{P}<0.05,{ }^{* *} \mathrm{P}<0.01$ and ${ }^{* * *} \mathrm{P}<0.01$ vs. control. ADK, adenosine kinase; BMMs, bone marrow macrophages; $\mathrm{ADK}^{\mathrm{WT}}$, ADK wild type; ADK ${ }^{\mathrm{MMC}-K O}$, ADK knockout in myeloid monocyte cells; TRAP, tartrate-resistant acid phosphatase; NFATc1, nuclear factor of activated T-cells, cytoplasmic 1; Control, untreated $\mathrm{ADK}^{\mathrm{WT}}$ mice.

Inhibition of ADK promotes osteoclastogenesis. To further understand whether spontaneous osteoporosis in $\mathrm{ADK}^{\mathrm{MMC}-\mathrm{KO}}$ mice is due to ADK inhibition, bone marrow macrophages (BMMs) were harvested from 2-month-old male ADK ${ }^{\mathrm{wT}}$ and $\mathrm{ADK}^{\mathrm{MMC}-\mathrm{KO}}$ mice. Western blotting revealed that the expression of ADK protein was significantly decreased in ADK $^{\text {MMC-KO }}$ compared with ADK $^{\text {WT }}$ mice (Fig. 3A, P<0.001). BMMs were subsequently exposed to M-CSF and RANKL for 8 days to induce osteoclastic differentiation. A TRAP assay was performed to reveal TRAP-positive cells and the typical multinucleated characteristics of in vitro differentiated osteoclasts were observed (Fig. 3B). Notably, larger TRAP-positive osteoclasts were observed in $\mathrm{ADK}^{\mathrm{MMC}-\mathrm{KO}}$ cultures compared with those from ADK ${ }^{\mathrm{WT}}$ mice (Fig. 3B). It was also demonstrated that BMMs derived from $\mathrm{ADK}^{\mathrm{MMC}-\mathrm{KO}}$ mice formed significantly more osteoclasts compared with those derived from $\mathrm{ADK}^{\mathrm{WT}}$ mice $(\mathrm{P}<0.01$; Fig. $3 \mathrm{~B})$. Factors associated with osteoclast formation were evaluated using RT-qPCR and the results indicated that relative levels of TRAP $(\mathrm{P}<0.01)$ and NFATc1 $(P<0.05)$ mRNA were significantly increased in $\mathrm{ADK}^{\mathrm{MMC}-\mathrm{KO}}$ osteoclasts compared with $\mathrm{ADK}^{\mathrm{WT}}$ osteoclasts (Fig. 3C); however, no significant difference was observed in c-FOS expression (Fig. 3C).

To further verify the role of ADK in osteoclast formation, the ADK inhibitor ABT-702 was applied to BMMs from $\mathrm{ADK}^{\mathrm{WT}}$ mice to induce osteoclastic differentiation (Fig. 3D). Treatment with $100 \mathrm{nM}$ ABT-702 significantly induced TRAP-positive osteoclast formation compared with untreated ADK ${ }^{\mathrm{WT}}$ BMMs (P<0.01; Fig. 3D). The expression of TRAP $(\mathrm{P}<0.05)$ and NFATc1 $(\mathrm{P}<0.05)$ mRNA was significantly increased by treatment with $100 \mathrm{nM}$ ABT0702 compared with untreated $\mathrm{ADK}^{\mathrm{WT}} \mathrm{BMMs}$, similar to $\mathrm{ADK}^{\mathrm{MMC}-\mathrm{KO}}$ cultures (Fig. 3E). These results suggest that ADK inhibition induces osteoclast formation.

ADK inhibition increases osteoclastic resorption activity. To investigate whether ADK inhibition affects osteoclastic resorption function, BMMs derived from 2-month-old male $\mathrm{ADK}^{\mathrm{WT}}$ and $\mathrm{ADK}^{\mathrm{MMC}-\mathrm{KO}}$ mice were incubated with $\mathrm{M}-\mathrm{CSF}$ and RANKL. Following 7 days of culture, the resorption area of osteoclasts induced from $\mathrm{ADK}^{\mathrm{MMC}-\mathrm{KO}} \mathrm{BMMs}$ was significantly greater than that of osteoclasts induced from $\mathrm{ADK}^{\mathrm{WT}} \mathrm{BMMs}$ $(\mathrm{P}<0.05$; Fig. 4A). Similarly, the number of resorption areas per well was significantly greater in the $\mathrm{ADK}^{\mathrm{MMC}-\mathrm{KO}}$ group compared with the ADK ${ }^{\mathrm{WT}}$ GROUP (P<0.05; Fig. 4A). Factors associated with osteoclast formation were further evaluated in these cultures using RT-qPCR the results demonstrated that relative levels of MMP9 $(\mathrm{P}<0.01)$, CtsK $(\mathrm{P}<0.001)$ and CTR $(\mathrm{P}<0.01)$ mRNA were significantly increased in $\mathrm{ADK}^{\mathrm{MMC}-\mathrm{KO}}$ osteoclasts compared with $\mathrm{ADK}^{\mathrm{WT}}$ osteoclasts (Fig. 4B). However, no significant difference was observed in $\mathrm{c}-\mathrm{Src}$ expression (Fig. 4B).

BMMs derived from $\mathrm{ADK}^{\mathrm{WT}}$ mice were also treated with $100 \mathrm{nM}$ ABT-702 to further evaluate the effect of ADK inhibition on osteoclastic resorption. The relative resorption area $(\mathrm{P}<0.001)$ and number of resorption areas per well $(\mathrm{P}<0.01)$ was significantly increased in cells treated with ABT-702 compared with untreated BMMs derived from $\mathrm{ADK}^{\mathrm{WT}}$ mice (Fig. 4C). The relative expression of MMP9 $(\mathrm{P}<0.01)$ and CtsK $(\mathrm{P}<0.05)$ mRNA was significantly increased in ABT-702 cultures compared with untreated BMMs derived from $\mathrm{ADK}^{\mathrm{WT}}$ mice (Fig. 4D). However, no significant difference was observed 

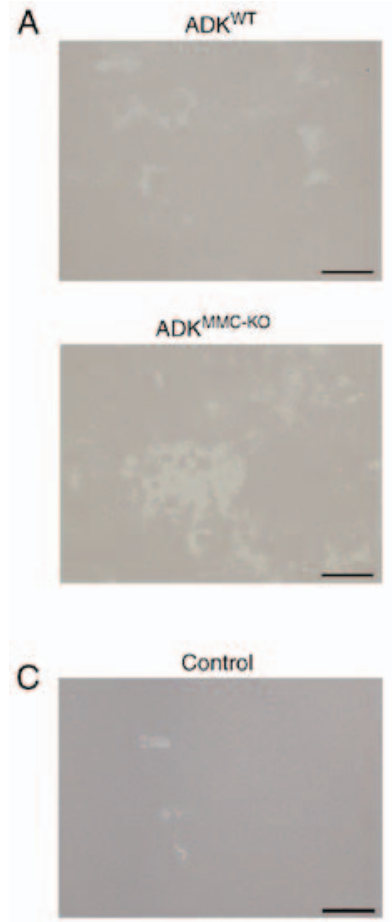

$100 \mathrm{nM}$ ABT-702

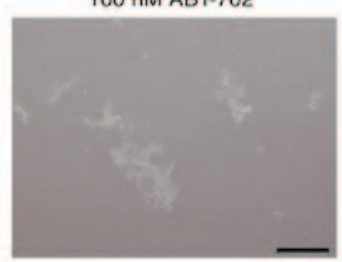

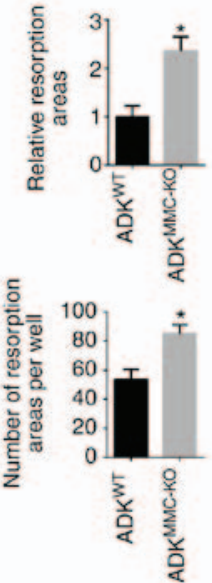
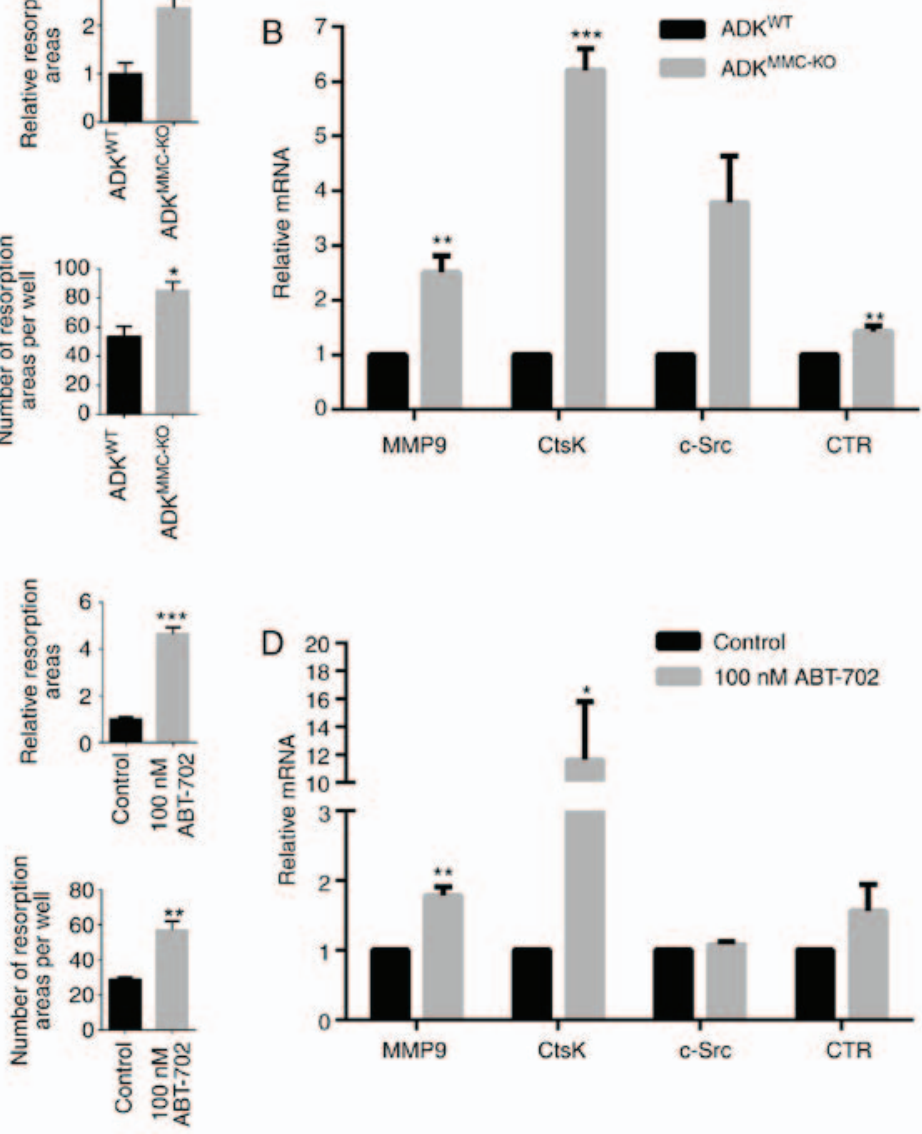

Figure 4. ADK knockdown enhances osteoclastic resorption activity and the expression of associated genes. (A) The resorption activity of osteoclasts generated from BMMs of $\mathrm{ADK}^{\mathrm{WT}}$ and $\mathrm{ADK}^{\mathrm{MMC}-\mathrm{KO}}$ mice. (B) Relative MMP9, CtsK, c-Src and CTR mRNA expression in osteoclasts generated from BMMs of $\mathrm{ADK}^{\mathrm{WT}}$ and $\mathrm{ADK}^{\mathrm{MMC}-\mathrm{KO}}$ mice. (C) The resorption activity of osteoclasts generated from BMMs of ADK ${ }^{\mathrm{WT}}$ treated with $100 \mathrm{nM}$ ABT-702. (D) Relative MMP9, CtsK, c-Src and CTR mRNA expression in osteoclasts generated from BMMs of ADK ${ }^{\mathrm{WT}}$ mice treated with $100 \mathrm{nM}$ ABT-702. Scale bar $=200 \mu \mathrm{m}$. ${ }^{*} \mathrm{P}<0.005,{ }^{* *} \mathrm{P}<0.01$ and ${ }^{* * *} \mathrm{P}<0.001$ vs. control. ADK, adenosine kinase; BMMs, bone marrow macrophages; ADK ${ }^{\mathrm{WT}}$, ADK wild type; ADK ${ }^{\mathrm{MMC}-\mathrm{KO}}$, ADK knockout in myeloid monocyte cells; MMP9, matrix metalloproteinase 9; c-FOS, FBJ osteosarcoma oncogene; CtsK, Cathepsin K; c-Src, proto-oncogene tyrosine-protein kinase Src; CTR, calcitonin receptor; Control, untreated ADKWT mice.

in c-Src and CTR levels (Fig. 4D). These results suggest that ADK inhibition may promote osteoclastic resorption activity

\section{Discussion}

In the present study, a mouse model with ADK deficient myeloid monocyte cells (ADK ${ }^{\mathrm{MMC}-\mathrm{KO}}$ ) was established by Cre/LoxP site-specific recombination. As a result of this conditional ADK knockout, spontaneous dwarfism associated with decreased bone mass was observed in adult mice. Further in vitro investigations based on genetic and pharmaceutical ADK disruption in bone marrow macrophages revealed that ADK inhibition significantly increases osteoclastogenesis and bone resorption in mouse BMMs. Collectively, these results suggest that ADK may be a potential target for the treatment of metabolic bone diseases associated with osteoclast.

Previous clinical studies have reported that human patients with global ADK deficiency due to homozygous point mutations exhibit developmental delay, including short stature, frontal bossing and slender hands and fingers $(16,25)$. A study involving homozygous disruption of the ADK gene in mice also reported reduced body size and weight within a few days of birth (1). In the present study, $\mathrm{ADK}^{\mathrm{MMC}-\mathrm{KO}}$ mice were characterized by spontaneous dwarfism, including reduced body weight, nasoanal length, and weight and length of tibia and femur. Histomorphometric analysis revealed significantly decreased bone mass in proximal tibia metaphysis and the middle of the tibial shaft in $\mathrm{ADK}^{\mathrm{MMC}-\mathrm{KO}}$ mice. Combined with previous reports, these results indicate that ADK may serve an important role in bone metabolism homeostasis.

Osteoclasts are highly specialized cells that are derived from the monocyte/macrophage lineage of the bone marrow (26). lys ${ }^{\text {cre }}$ mice have been used extensively to investigate osteoclast function in previous studies (27-29). In the present study, osteoclastic changes in $\mathrm{ADK}^{\mathrm{MMC}-\mathrm{KO}}$ mice were assessed in vivo using histomorphometric analysis and in vitro using a BMM cell culture. The results revealed increased osteoclastic parameters, including osteoclastogenesis and bone resorption, associated with ADK deficiency. Histomorphometric analysis also demonstrated that the function of osteoblasts derived from pluripotent mesenchymal stem cells was inhibited in $\mathrm{ADK}^{\mathrm{MMC}-\mathrm{KO}}$ mice, suggesting that purinergic signaling from ADK-deficient activated osteoclasts may affect osteoblasts by interacting with adenosine receptors (10). Furthermore, the 
exosomes derived from activated osteoclasts may also inhibit osteoblast activity (30).

ADK converts intracellular adenosine to AMP; ADK deficiency or dysfunction results in the accumulation of intracellular adenosine (1). Adenosine may be transported to the extracellular environment by type 1 equilibrative nucleoside transporter (ENT1) (31); as such, the ADK-deficiency-induced accumulation of intracellular adenosine may result in adenosine being transported to the extracellular environment by ENT to interact with adenosine receptors, including A1R $(32,33)$ and A2BR $(34,35)$, to promote osteoclast differentiation. However, mice lacking ENT1 have been reported to have reduced weight and lower bone density in the spine and femur associated with increased osteoclast activity (36). This suggests that intracellular adenosine may also participate in the functional regulation of osteoclasts via a receptor independent pathway, although this requires further investigation.

Metabolic analysis of liver tissue homogenates from homozygous ADK deficient mice revealed a 40\% decrease in AMP and ADP and a $35 \%$ decrease in ATP (17). A previous study utilizing osteoclast-specific conditional knockout Tfam mice, in which ATP production is inhibited in osteoclasts, reported reduced growth and increased bone-resorption (37). An in vitro study demonstrated that ATP inhibits the differentiation of osteoclast-like cells from RANKL-induced RAW cells (38). A number of studies have reported that metformin is able to effectively improve osteoporosis in patients with long-term type 2 diabetes mellitus by inhibiting osteoclast differentiation (39-41). The mechanism by this is achieved is associated with the activation of AMP-activated protein kinase (AMPK), a 'metabolic master switch' downstream of ADK (42-44). It was therefore speculated that prolonged ADK deficiency in myeloid monocyte cells may result in disordered purinergic signaling, which may contribute to bone growth retardation and excessive osteoclast differentiation and activation in $\mathrm{ADK}^{\mathrm{MMC}-\mathrm{KO}}$ mice.

In summary, the results of the present study suggest that ADK deficient myeloid monocyte cells contribute to reduced bone formation in mice and this is associated with osteoclastogenesis and bone resorption in $\mathrm{ADK}^{\mathrm{MMC}-\mathrm{KO}}$ mice.

\section{Acknowledgements}

The authors would like to thank Professor Yuqing Huo for providing the ADK conditional knockout mice. The present study was supported by the Guangdong Provincial Science \& Technology Project (grant nos. 2013B060300025, 2015A030303006 and 2016A030313790 to G.L.) and the Natural Science Foundation of China (grant nos. 31702074 to G.L. and 31472061 to Y.Z.).

\section{Competing interests}

The authors declare that they have no competing interests.

\section{References}

1. Boison D: Adenosine kinase: Exploitation for therapeutic gain. Pharmacol Rev 65: 906-943, 2013.

2. Andres CM and Fox IH: Purification and properties of human placental adenosine kinase. J Biol Chem 254: 11388-11393, 1979.
3. Antonioli L, Blandizzi C, Pacher P and Haskó G: Immunity, inflammation and cancer: A leading role for adenosine. Nat Rev Cancer 13: 842-857, 2013.

4. Boison D: The adenosine kinase hypothesis of epileptogenesis. Prog Neurobiol 84: 249-262, 2008.

5. Lusardi TA, Lytle NK, Szybala C and Boison D: Caffeine prevents acute mortality after TBI in rats without increased morbidity. Exp Neurol 234: 161-168, 2012.

6. Pignataro G, Simon RP and Boison D: Transgenic overexpression of adenosine kinase aggravates cell death in ischemia. J Cereb Blood Flow Metab 27: 1-5, 2007.

7. Pawelczyk T, Sakowicz M, Szczepanska-Konkel M and Angielski S: Decreased expression of adenosine kinase in streptozotocin-induced diabetes mellitus rats. Arch Biochem Biophys 375: 1-6, 2000.

8. Giglioni S, Leoncini R, Aceto E, Chessa A, Civitelli S, Bernini A, Tanzini G, Carraro F, Pucci A and Vannoni D: Adenosine kinase gene expression in human colorectal cancer. Nucleosides Nucleotides Nucleic Acids 27: 750-754, 2008.

9. Raggatt LJ and Partridge NC: Cellular and molecular mechanisms of bone remodeling. J Biol Chem 285: 25103-25108, 2010.

10. Mediero A and Cronstein BN: Adenosine and bone metabolism. Trends Endocrinol Metab 24: 290-300, 2013.

11. He W, Mazumder A, Wilder T and Cronstein BN: Adenosine regulates bone metabolism via $\mathrm{A} 1, \mathrm{~A} 2 \mathrm{~A}$, and $\mathrm{A} 2 \mathrm{~B}$ receptors in bone marrow cells from normal humans and patients with multiple myeloma. FASEB J 27: 3446-3454, 2013.

12. He W and Cronstein BN: Adenosine A1 receptor regulates osteoclast formation by altering TRAF6/TAK1 signaling. Purinergic Signal 8: 327-337, 2012.

13. Mediero A, Kara FM, Wilder T and Cronstein BN: Adenosine A2A receptor ligation inhibits osteoclast formation. Am J Pathol 180: 775-786, 2012.

14. Corciulo C, Wilder T and Cronstein BN: Adenosine A2B receptors play an important role in bone homeostasis. Purinergic Signal 12: 537-547, 2016.

15. Rath-Wolfson L, Bar-Yehuda S, Madi L, Ochaion A, Cohen S, Zabutti A and Fishman P: IB-MECA, an A3 adenosine receptor agonist prevents bone resorption in rats with adjuvant induced arthritis. Clin Exp Rheumatol 24: 400-406, 2006.

16. Staufner C, Lindner M, Dionisi-Vici C, Freisinger P, Dobbelaere D, Douillard C, Makhseed N, Straub BK, Kahrizi K, Ballhausen D, et al: Adenosine kinase deficiency: Expanding the clinical spectrum and evaluating therapeutic options. J Inherit Metab Dis 39: 273-283, 2016.

17. Boison D, Scheurer L, Zumsteg V, Rülicke T, Litynski P, Fowler B, Brandner S and Mohler H: Neonatal hepatic steatosis by disruption of the adenosine kinase gene. Proc Natl Acad Sci USA 99: 6985-6990, 2002.

18. Massaro EJ and Rogers JM (eds.): The Skeleton: Biochemical, Genetic, and Molecular Interactions in Development and Homeostasis. Humana Press, Totowa, NJ, 2004.

19. Sandau US, Colino-Oliveira M, Jones A, Saleumvong B, Coffman SQ, Liu L, Miranda-Lourenço C, Palminha C, Batalha VL, Xu Y, et al: Adenosine kinase deficiency in the brain results in maladaptive synaptic plasticity. J Neurosci 36: 12117-12128, 2016.

20. Clausen BE, Burkhardt C, Reith W, Renkawitz R and Förster I: Conditional gene targeting in macrophages and granulocytes using LysMcre mice. Transgenic Res 8: 265-277, 1999.

21. Takahashi N, Udagawa N, Tanaka S and Suda T: Generating murine osteoclasts from bone marrow. Methods Mol Med 80: 129-144, 2003

22. Tevlin R, McArdle A, Chan CK, Pluvinage J, Walmsley GG, Wearda T, Marecic O, Hu MS, Paik KJ, Senarath-Yapa K, et al: Osteoclast derivation from mouse bone marrow. J Vis Exp 6: e52056, 2014

23. Livak KJ and Schmittgen TD: Analysis of relative gene expression data using real-time quantitative PCR and the 2(-Delta Delta C(T)) method. Methods 25: 402-408, 2001.

24. Dempster DW, Compston JE, Drezner MK, Glorieux FH, Kanis JA, Malluche H, Meunier PJ, Ott SM, Recker RR and Parfitt AM: Standardized nomenclature, symbols, and units for bone histomorphometry: A 2012 update of the report of the ASBMR Histomorphometry nomenclature committee. J Bone Miner Res 28: 2-17, 2013.

25. Bjursell MK, Blom HJ, Cayuela JA, Engvall ML, Lesko N, Balasubramaniam S, Brandberg G, Halldin M, Falkenberg M, Jakobs C, et al: Adenosine kinase deficiency disrupts the methionine cycle and causes hypermethioninemia, encephalopathy, and abnormal liver function. Am J Hum Genet 89: 507-515, 2011. 
26. Boyle WJ, Simonet WS and Lacey DL: Osteoclast differentiation and activation. Nature 423: 337-342, 2003.

27. Albers J, Keller J, Baranowsky A, Beil FT, Catala-Lehnen P, Schulze J, Amling M and Schinke T: Canonical Wnt signaling inhibits osteoclastogenesis independent of osteoprotegerin. J Cell Biol 200: 537-549, 2013.

28. Bartell SM, Kim HN, Ambrogini E, Han L, Iyer S, Serra Ucer S, Rabinovitch P, Jilka RL, Weinstein RS, Zhao H, et al: FoxO proteins restrain osteoclastogenesis and bone resorption by attenuating $\mathrm{H}_{2} \mathrm{O}_{2}$ accumulation. Nat Commun 5: 3773, 2014.

29. Kim HN, Han L, Iyer S, de Cabo R, Zhao H, O'Brien CA Manolagas SC and Almeida M: Sirtuin1 suppresses osteoclastogenesis by deacetylating FoxOs. Mol Endocrinol 29: 1498-1509, 2015.

30. Sun W, Zhao C, Li Y, Wang L, Nie G, Peng J, Wang A, Zhang P, Tian W, Li Q, et al: Osteoclast-derived microRNA-containing exosomes selectively inhibit osteoblast activity. Cell Discov 2: $16015,2016$.

31. Young JD, Yao SY, Sun L, Cass CE and Baldwin SA: Human equilibrative nucleoside transporter (ENT) family of nucleoside and nucleobase transporter proteins. Xenobiotica 38: 995-1021, 2008.

32. Kara FM, Chitu V, Sloane J, Axelrod M, Fredholm BB, Stanley ER and Cronstein BN: Adenosine A1 receptors (A1Rs) play a critical role in osteoclast formation and function. FASEB J 24: 2325-2333, 2010.

33. Kara FM, Doty SB, Boskey A, Goldring S, Zaidi M, Fredholm BB and Cronstein BN: Adenosine A(1) receptors regulate bone resorption in mice: Adenosine A(1) receptor blockade or deletion increases bone density and prevents ovariectomy-induced bone loss in adenosine A(1) receptor-knockout mice. Arthritis Rheum 62: 534-541, 2010.

34. Carroll SH, Wigner NA, Kulkarni N, Johnston-Cox H, Gerstenfeld LC and Ravid K: A2B adenosine receptor promotes mesenchymal stem cell differentiation to osteoblasts and bone formation in vivo. J Biol Chem 287: 15718-15727, 2012.
35. Gharibi B, Abraham AA, Ham J and Evans BA: Adenosine receptor subtype expression and activation influence the differentiation of mesenchymal stem cells to osteoblasts and adipocytes. J Bone Miner Res 26: 2112-2124, 2011.

36. Hinton DJ, McGee-Lawrence ME, Lee MR, Kwong HK, Westendorf JJ and Choi DS: Aberrant bone density in aging mice lacking the adenosine transporter ENT1. PLoS One 9: e88818, 2014.

37. Tsuchiya A, Kanno T, Saito M, Miyoshi Y, Gotoh A, Nakano T and Nishizaki T: Intracellularly transported adenosine induces apoptosis in (corrected) MCF-7 human breast cancer cells by accumulating AMID in the nucleus. Cancer Lett 321: 65-72, 2012.

38. Hiken JF and Steinberg TH: ATP downregulates P2X7 and inhibits osteoclast formation in RAW cells. Am J Physiol Cell Physiol 287: C403-C412, 2004.

39. Paschou SA, Dede AD, Anagnostis PG, Vryonidou A Morganstein D and Goulis DG: Type 2 diabetes and osteoporosis: A guide to optimal management. J Clin Endocrinol Metab 102: 3621-3634, 2017.

40. Hegazy SK: Evaluation of the anti-osteoporotic effects of metformin and sitagliptin in postmenopausal diabetic women. J Bone Miner Metab 33: 207-212, 2015.

41. Montagnani A, Gonnelli S, Alessandri $M$ and Nuti R: Osteoporosis and risk of fracture in patients with diabetes: An update. Aging Clin Exp Res 23: 84-90, 2011.

42. Lee YS, Kim YS, Lee SY, Kim GH, Kim BJ, Lee SH, Lee KU, Kim GS, Kim SW and Koh JM: AMP kinase acts as a negative regulator of RANKL in the differentiation of osteoclasts. Bone 47: 926-937, 2010.

43. Mai QG, Zhang ZM, Xu S, Lu M, Zhou RP, Zhao L, Jia CH, Wen ZH, Jin DD and Bai XC: Metformin stimulates osteoprotegerin and reduces RANKL expression in osteoblasts and ovariectomized rats. J Cell Biochem 112: 2902-2909, 2011.

44. McCarthy AD, Cortizo AM and Sedlinsky C: Metformin revisited: Does this regulator of AMP-activated protein kinase secondarily affect bone metabolism and prevent diabetic osteopathy. World J Diabetes 7: 122-133, 2016. 